\title{
Unlocking the Hidden Dimension of the World's Transmission and Distribution Power Losses through Fractal Statistical Inference
}

\author{
Jhovie Chleo Tan¹, Audrey Mae L. Escala², Jessa Marie E. Francisco ${ }^{3}$, \\ Elvira S. Pecajas ${ }^{4}$, Edison R. Ralar ${ }^{5}$ \\ ${ }^{1-5}$ Biliran Province State University, Naval, Biliram, Philippines \\ Corresponding Author: Elvira S. Pecajas
}

\begin{abstract}
Various studies on the transmission and distribution power losses had been conducted but a global view of the transmission and distribution power loss rates had not been explored yet. This paper explained the fractal dimension of the global distribution and transmission power losses using fractal statistical analysis. Findings revealed that the computed fractal dimension of 1.08 means that power losses of countries across the globe deviated from uniformity by about 8 percent. The upper and bottom eight (8) percent of the dataset were analyzed and findings revealed that the ruggedness of the phenomenon was attributable to political and economic dimensions. The extreme high distribution and transmission power losses may be traced back to chaos, pilferage, and substandard materials. On the other hand, the economic stability and state control capacity contributed much to the extreme low distribution and transmission power losses.
\end{abstract}

Keywords: fractal analysis, power loss, power transmission and distribution, xfractal

\section{INTRODUCTION}

Electricity is an essential resource in all sectors of the society. Power generated in power stations pass through large and complex networks like transformers, overhead lines, cables and other equipment and reaches at the end users. It is a fact that the unit of electric generated by power station does not match with the units distributed to the consumers. Some percentage of the units is lost in the distribution network. The difference in the generated and distributed units is known as transmission and distribution losses. Transmission and distribution losses are the amounts that are not paid for by users. Losses in the transmission and distribution may be classified as technical and nontechnical. The technical losses are due to energy dissipated in the conductors, equipment used for transmission line, transformer, sub-transmission line and distribution line and magnetic losses in transformers. Non-technical (commercial) losses are due to theft and pilferage of energy committed by non-consumers and bonafide consumers.

According to the World Bank report (2013), the average annual calculated electric power transmission and distribution (T\&D) losses in the world is about 8 percent. This annual figure represents the difference between the sources of supply and points of distribution to consumers. The losses percentage span from 3 percent to rates as high as 55 percent. The divergent performances of different power grids can be explained and attributed to controllable factors and to uncontrollable factors. Some key factors are known; others are not and are constantly being investigated. Knowledge of what factors increase or decrease the power losses makes it possible 
to optimize the grid with respect to the power losses (Sempler, 2014).

This study obtained the global view and explanations of the fractal dimension of the 2013 global T \& D power losses data of the 162 countries using fractal statistical analysis.

The Fractal Statistical Analysis (FSA) of Padua (2015) has revolutionized the possibility of analyzing non-normal data set. Furthermore, the transmission and distribution power losses among countries worldwide can be analyzed through FSA's lens. Hence, this paper attempts to reveal the trend of the distribution and transmission power losses in its natural state hoping to unlock some hidden dimensions.

\section{METHODOLOGY}

This study utilized the fractal statistical analysis of Padua (2015). The secondary data on the $\mathrm{T} \& \mathrm{D}$ power losses across the globe (2013) was retrieved from the World Bank website (2021). The fractal dimension was determined to show roughness or ruggedness of the distribution.

Padua's theorem (2015) was used to test the fractality of the distribution which states that " $\mathrm{x}$ is fractal if and only if log $(\mathrm{x} / \theta)$ has an exponential distribution with a rate parameter of lambda-1".

The fractal dimension lambda was computed using the formula $\lambda=1+\frac{1}{\bar{y}}$

\section{RESULTS AND DISCUSSION}

Figure 1 below shows the frequency distribution of the $\mathrm{T} \& \mathrm{D}$ power losses of the 162 countries

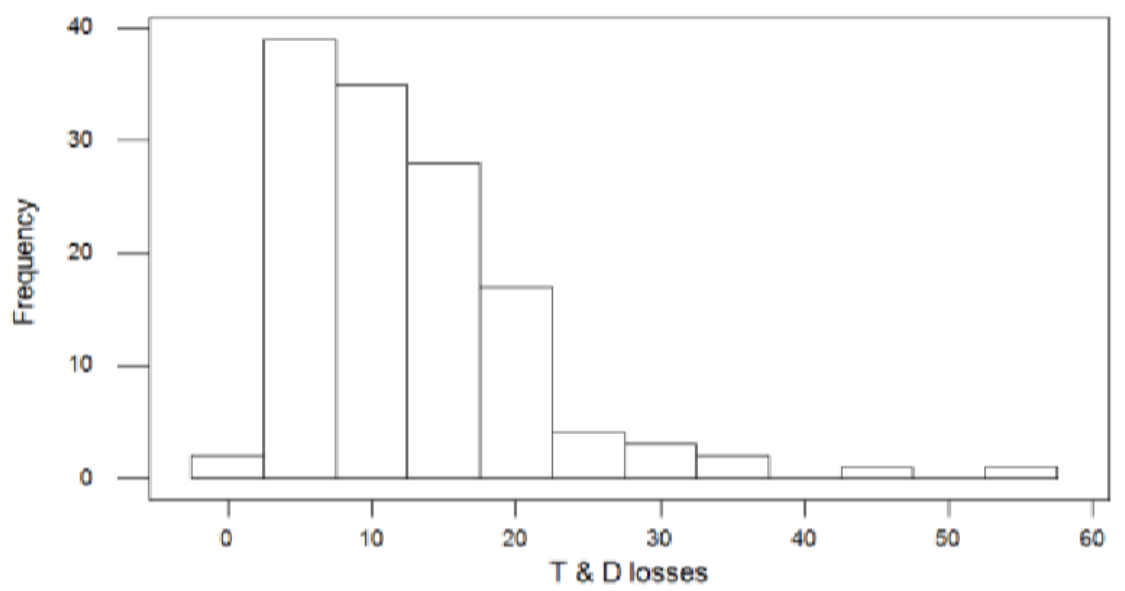

Figure 1 divulged that the frequency distribution is apparently in exponential state. To verify the fractality of the dataset, the exponential representation of the percent T \& D losses was determined and plotted in Figure 2 below.

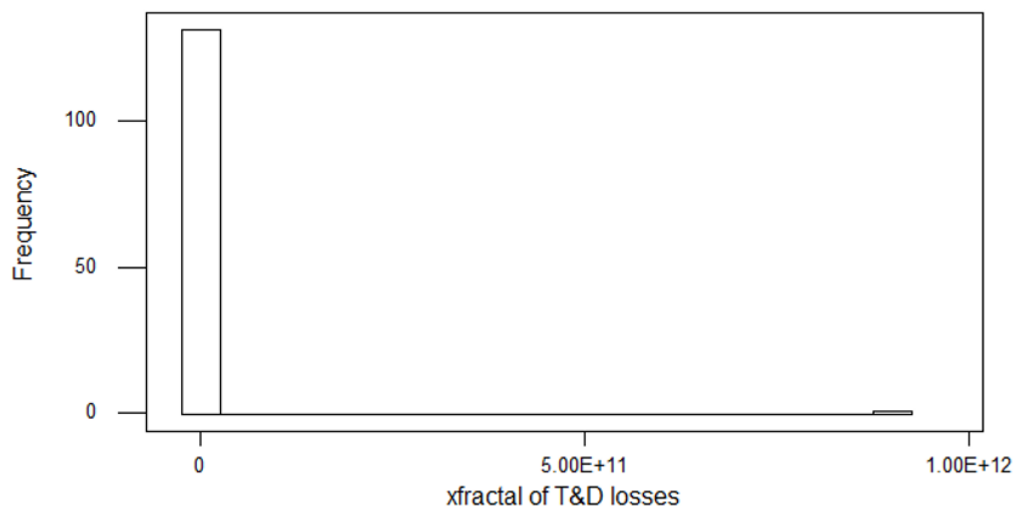


As shown in Figure 2, the exponential distribution shows a one-stroke characteristics, thus the dataset of the xfractal verifies that the distribution is indeed fractal.

Table 1 below shows number of countries, the mean percentage, the minimum value, and the computed fractal dimension of the distribution of $\mathrm{T} \& \mathrm{D}$ power losses of the countries across the globe.

Table 1. Distribution of T \& D Losses of the Countries across the Globe

\begin{tabular}{|c|c|c|c|}
\hline $\mathbf{N}$ & $\begin{array}{c}\text { Mean } \\
\text { Percentage }\end{array}$ & $\begin{array}{c}\text { Minimum } \\
\text { Value }\end{array}$ & $\begin{array}{c}\text { Fractal } \\
\text { Dimension }\end{array}$ \\
\hline 162 & 12.856 & 2.00 & 1.08 \\
\hline
\end{tabular}

It can be gleaned from Table 1 that among the 162 countries, the mean percentage loss was 12.856 percent with a minimum percentage value of 2.00 percent. The computed fractal dimension lambda reached 1.08. This implies that the distribution of the $\mathrm{T} \& \mathrm{D}$ power losses of the countries across the globe deviated from normality by about 8 percent.

Table 2 presents the ranking of the top 13 countries or 8 percent of the 162 countries which obtained the largest T \& D power losses.

Table 2. Top Eight (8) Percent of the Countries with Highest T \& D Power Losses

\begin{tabular}{|c|c|c|}
\hline No. & Countries & T \& D Losses \\
\hline 1 & Haiti & 54.60 \\
\hline 2 & Congo, Rep & 46.02 \\
\hline 3 & Iraq & 34.76 \\
\hline 4 & Nepal & 34.33 \\
\hline 5 & Dominican Republic & 30.13 \\
\hline 6 & Cambodia & 28.11 \\
\hline 7 & Other Small Sates & 27.97 \\
\hline 8 & Namibia & 27.90 \\
\hline 9 & Yemen, Rep & 27.34 \\
\hline 10 & Albania & 25.13 \\
\hline 11 & Zambia & 23.70 \\
\hline 12 & Cote d'Ivoire & 22.38 \\
\hline 13 & Sudan & 21.92 \\
\hline
\end{tabular}

It can be noted from Table 2 above that among the top 13 countries or 8 percent of the 162 countries obtaining the highest T \& D loss was Haiti. The lowest T \& D loss was obtained by Sudan.

The flowing information/background are being forwarded in the hope of giving explanations to the hidden fractal dimension of the global distribution and transmission of 13 countries which obtained the largest $\mathrm{T}$ \& D power losses as of 2013: top 13 countries have problems on economy, political chaos, pilferage, and sub-standard materials.

Table 3. below presents the bottom eight (8) percent of the 162 countries with the least $\mathrm{T} \& \mathrm{D}$ losses.

Table 3. Bottom Eight (8) Percent of the 162 Countries with Least T \& D losses

\begin{tabular}{|c|c|c|}
\hline No. & Countries & T \& D Losses \\
\hline 1 & Slovak Republic & 1.82 \\
\hline 2 & Qatar & 2.03 \\
\hline 3 & Israel & 2.75 \\
\hline 4 & Iceland & 2.92 \\
\hline 5 & Cyprus & 3.25 \\
\hline 6 & Korea, Rep & 3.35 \\
\hline 7 & Finland & 3.44 \\
\hline 8 & Zimbabwe & 3.79 \\
\hline 9 & Netherlands & 4.08 \\
\hline 10 & Germany & 4.27 \\
\hline 11 & Japan & 4.62 \\
\hline 12 & Belgium & 4.67 \\
\hline 13 & Greece & 4.77 \\
\hline
\end{tabular}

Table 3 divulged that among the 13 countries having the least T \& D losses, Slovak Republic obtained the lowest T \& D loss of 1.82 percent; while Greece got 4.77 percent T \& D loss.

The following information/ background are being forwarded in the hope of giving explanations to the fractal dimension of the global distribution and transmission of 13 countries which obtained the least T \& D power losses as of 2013: all of the 13 countries have strong and stable economy and no political chaos.

\section{CONCLUSION}

The Fractal Statistical Analysis revealed that distribution and transmission power losses among countries worldwide is fractal. The ruggedness of the phenomenon is attributable to political and economic dimensions. The extreme high distribution and transmission power losses may be traced back to chaos, pilferage, and substandard materials. On the other hand, the economic stability and state control capacity contributed much to the extreme low distribution and transmission power losses. 
Jhovie Chleo Tan et.al. Unlocking the hidden dimension of the world's transmission and distribution power losses through fractal statistical inference.

Acknowledgement: None

Conflict of Interest: None

\section{Source of Funding: None}

\section{REFERENCES}

1. Bowles, M. (2010) "State Electricity Profiles 2008)," US Energy Information Administration, DOE/EIA 0348(01)/2.

2. Gill, P.(2009). Electrical Power Equipment Maintenance and Testing, Second Edition, CRC Press: Taylor \& Francis Group, LL
3. Mandelbrot, Benoit B. (1983). The Fractal geometry of nature. Macmillan. ISBN 9780-7167-1186-5. Retrieved April 2, 2021.

4. Data.worldbank.org/T\&D losses

How to cite this article: Jhovie Chleo Tan, Audrey Mae L. Escala, Jessa Marie E. Francisco et.al. Unlocking the hidden dimension of the world's transmission and distribution power losses through fractal statistical inference. International Journal of Research and Review. 2021; 8(12): 634-637. DOI: https://doi.org/10.52403/ijrr.20211277 